\title{
Pesquisa de anticorpos contra Brucella sp. em soros de eqüinos com e sem abscesso de cernelha
}

\section{Investigation of antibodies to Brucella sp. in sera of equine with and without fistulous withers}

\author{
Luis Antonio Mathias, ${ }^{*}$ Valmir Tunala, ** José Correa de Lacerda Neto,,** Raul José Silva Gírio*
}

\begin{abstract}
Resumo
Com o objetivo de verificar a relação entre a presença de anticorpos contra Brucella sp. e de sintomas compatíveis com brucelose, foram examinados soros de 50 eqüinos com abscesso de cernelha e de 50 eqüinos sem esse sintoma. Os soros foram submetidos às provas de soroaglutinação em placa, fixação de complemento e rosa Bengala. Analisandose, pelo teste de $X^{2}$, a relação entre a presença ou não de abscesso de cernelha e os resultados obtidos nos testes sorológicos, observou-se uma dependência entre a distribuição das freqüências $(P>0,005)$, com o $X^{2}$ apresentando valores de 12,39 para a prova de soroaglutinação, adotando-se como ponto de corte o título 1/100; 16,06, mas adotandose o título 1/50 como ponto de corte; de 16,53 para o teste rosa Bengala; e de 18,04 para a reação de fixação de complemento. Os resultados deste trabalho mostram que, embora a presença de abscesso de cernelha em eqüinos nem sempre esteja associada à brucelose, existe uma forte relação entre aquele sintoma e a presença de anticorpos contra Brucella sp., e que a reação de fixação de complemento foi a prova que apresentou maior proporção de resultados negativos entre os animais sem o sintoma.
\end{abstract}

Palavras-chave: Brucelose eqüina; diagnóstico sorológico.

\section{Introdução}

A brucelose é um doença infecciosa que pode atingir diversas espécies animais, entre elas os eqüinos. Embora essa espécie animal não seja um hospedeiro importante para o agente etiológico da enfermidade, não se constituindo em reservatório para nenhuma das espécies conhecidas do gênero Brucella, os eqüinọs podem sofrer uma infecção com graves conseqüências para o animal.

O eqüino geralmente é infectado quando da convivência com outras espécies animais (principalmente bovinos), hospedeiras das bactérias desse gênero, sendo admitido que possam tornar-se fonte potencial de infecção, embora não haja relato de casos comprovados de brucelose transmitidos por essa espécie animal.

Diversos trabalhos (Langenegger e Szechy, 1961 ; Oliveira et al., 1973 ; Jardim et al., 1978 ; Viana et al., 1981) mostram que é freqüente a ocorrência de brucelose em eqüinos no Brasil, o que pode ser explicado, principalmente, pela convivência com rebanhos bovinos, nos quais a brucelose é endêmica.
A brucelose eqüina pode apresentar-se de três formas: 1) forma assintomática ou latente; 2) com sintomas gerais, principalmente febre; e 3) uma forma na qual ocorrem lesões localizadas, tais como bursites, artrites e tendinites (Denny, 1973).

Embora a presença de lesões na região da cernelha ou da nuca (um dos sintomas clássicos da brucelose em eqüídeos), seja prontamente associada com essa infecção, a forma latente é, provavelmente, a de ocorrência mais comum (Denny, 1973). Deve-se mencionar, ainda, que esse sintoma também pode ser causado por outros agentes infecciosos, tais como Streptococcus sp., Corynebacterium sp. e Actinomyces bovis (Gaughan et al., 1988), além de agentes físicos (traumatismos) e do parasita Onchocerca cervicalis (Rashmir-Raven et al., 1990).

O fato de ser comum a infecção inaparente e também de o principal sintoma poder ser causado por outros agentes enfatizam a necessidade do uso de técnicas que proporcionem um diagnóstico confiável. Várias técnicas sorológicas têm sido avaliadas para uso nesse diagnóstico (Dawson, 1977; O'Sullivan, 1981), sendo que no Brasil

\footnotetext{
* Departamento de Medicina Veterinária Preventiva - FCAVJ-Unesp - 14870-000 - Jaboticabal-SP-Brasil.

** Serviço de Inspeção Federal - MARA - Araguari-MG.

*** Departamento de Clínica e Cirurgia Veterinária - FCAVJ-Unesp.
} 
a prova de soroaglutinação em placa é a mais freqüentemente utilizada. Entretanto, é comum a observação de animais com títulos de anticorpos nessa prova, mesmo em eqüinos que não convivem com outras espécies animais que possam ser consideradas reservatórios de Brucella sp., como observaram Godoy e Barg (1976), em eqüinos de corrida, criados separados de outras espécies animais, levando a supor que parte dessas reações pode ser falso-positiva.

Outro aspecto polêmico é o título a partir do qual se deve considerar o resultado como positivo. Langenegger e Szechy (1961) adotaram o título 1/50 como suspeito e 1/ 100 como positivo, enquanto que Denny (1973) considera significativo o título $1 / 40$ na prova de soroaglutinação. Cohen et al. (1992) afirmam que o título $1 / 50$ já pode ser considerado positivo, mas, em sua publicação, adotam o título 1/100 como limiar de positividade.

Os aspectos mencionados realçam a importância de se utilizar testes que possibilitem um diagnóstico mais confiável para a brucelose eqüina. Dessa forma, o presente trabalho foi desenvolvido com o objetivo de verificar a relação entre a ocorrência de abscesso de cernelha e a presença de anticorpos contra Brucella sp. detectados pelas provas de soroaglutinação em placa, rosa Bengala e fixação de complemento.

\section{Material e métodos}

\section{Animais examinados}

Foram obtidos soros de 50 eqüinos adultos, apresentando abscesso de cernelha, abatidos no Frigorífico de AraguariMG, no ano de 1994. A título de comparação, foram obtidos também 50 soros de eqüinos adultos que não apresentavam abscesso de cernelha, abatidos no mesmo frigorífico.

\section{Prova de soroaglutinação em placa}

A prova de soroaglutinação em placa foi realizada de acordo com a técnica padrão usualmente empregada no diagnóstico sorológico da brucelose animal (Centro Panamericano de Zoonosis, 1968), usando-se antígeno padronizado, preparado com Brucella abortus amostra 1119/3, pelo Instituto de Tecnologia do Paraná (Tecpar).

Para efeito da análise estatística, avaliou-se o desempenho do teste, adotando-se como ponto de corte o título $1 / 50$ e também o título $1 / 100$.

\section{Teste rosa Bengala}

O teste rosa Bengala foi realizado de acordo com as recomendações de Alton et al. (1988), empregando-se antígeno preparado com Brucella abortus amostra 1119/3, pelo Instituto de Tecnologia do Paraná (Tecpar).

\section{Reação de fixação de complemento}

Foi empregada a microtécnica com incubação a $37^{\circ} \mathrm{C}$ nas duas fases da reação, recomendada por Alton et al. (1988). Foi utilizado o antígeno preparado para a prova de soroaglutinação em tubos, produzido pelo Tecpar. Para efeito da análise estatística, considerou-se como positivo o soro apresentando título maior ou igual a 1/4.

\section{Análise estatística}

Para se verificar a relação entre a presença de abscesso de cernelha e o resultado dos testes sorológicos, empregou-se o teste de $X^{2}$.

A concordância entre os testes foi calculada de acordo com a seguinte fórmula (Martin et al., 1987):

Positivos ambos os testes + negativos ambos os testes

Número de animais examinados

\section{Resultados}

Dos soros de eqüinos clinicamente sadios, 49 foram submetidos às provas de soroaglutinação em placa e rosa Bengala (1 não tinha volume suficiente para análise), e 48 desses soros foram submetidos à reação de fixação de complemento (2 apresentaram atividade anticomplementar). Dos 50 soros de animais com abscesso de cernelha, todos foram testados pela reação de fixação de complemento e 48 pelas provas de soroaglutinação em placa e rosa Bengala (2 não apresentaram volume suficiente para serem testados por essas duas provas).

De 49 animais clinicamente sadios, 36 (73,5\%) não apresentaram título na prova de soroaglutinação em placa e $9(18,4 \%)$ apresentaram título $1 / 25$, enquanto $2(4,1 \%)$ apresentaram título $1 / 50$ e outros $2(4,1 \%)$ apresentaram título 1/100. De 48 eqüinos com abscesso de cernelha, $24(50,0 \%)$ não apresentaram título e $3(6,3 \%)$ apresentaram título $1 / 25$, ao passo que títulos de $1 / 50$, $1 / 100,1 / 200$ e maiores ou iguais a $1 / 400$ foram apresentados por $6(12,5 \%), 7(14,6 \%), 4$ (8,3\%) e 4 (8,3\%) animais, respectivamente (Tabela 1). Considerando-se positivos os títulos a partir de 1/50, na comparação entre os resultados do teste e a presença ou não do abscesso de cernelha, a análise estatística mostrou uma dependência na distribuição de freqüências $(P>0,005)$, com o $\mathrm{X}^{2}$ apresentando valor de 16,06; considerando-se como ponto de corte o título $1 / 100$, também se observou dependência na distribuição de freqüências, e o $X^{2}$ apresentou valor de 12,39.

Na Tabela 2 pode-se observar que $47(97,9 \%)$ dos animais clinicamente sadios não apresentaram título na reação de fixação de complemento e 1 animal $(2,1 \%)$ apresentou título 1/8. Já entre os animais com abscesso de cernelha, uma proporção bem menor, 62,0\% (ou seja, 31 de 50 animais), não apresentou título nessa prova, 
enquanto $18(36,0 \%)$ animais apresentaram título a partir de $1 / 4$, tendo sido observados até títulos maiores ou iguais a 1/256. Comparando-se os títulos observados em animais com e sem o sintoma, observou-se uma dependência na distribuição das freqüências $(P>0,005)$, com um $X^{2}$ de 18,05 .

O teste rosa Bengala (Tabela 3) apontou $47(95,9 \%)$ animais com resultado negativo e $2(4,1 \%)$ com resultado positivo entre 49 eqüinos sem abscesso de cernelha, e $30(62,5 \%)$ animais com resultado negativo e 18 (37,5\%) com resultado positivo entre 48 animais com abscesso de cernelha. Observou-se um valor de 16,53 para o $X^{2}$, o que significa uma dependência entre os resultados do teste e a presença do sintoma $(P>0,005)$.

Comparando-se os resultados obtidos entre os animais clinicamente sadios, observou-se uma concordância de $95,9 \%$ entre o teste rosa Bengala e a prova de soroaglutinação em placa (1/50 como ponto de corte), uma vez que, de 47 animais negativos no rosa Bengala, 2 apresentaram título $1 / 50$ na soroaglutinação. Ao se adotar o título $1 / 100$ como ponto de corte, a concordância aumentou para $100,0 \%$. Já analisando-se os resultados obtidos entre animais com abscesso de cernelha, observa-se que a concordância entre os dois testes (que foi de $93,7 \%$ adotando-se o título de $1 / 50$ na prova de soroaglutinação), diminuiu para $85,4 \%$ quando se adotou o título $1 / 100$ como limiar de positividade (Tabela 4).

A concordância entre a fixação de complemento e a soroaglutinação $(1 / 50)$ foi de $89,4 \%$, para animais clinicamente sadios, com 4 dos 46 soros negativos na fixação de complemento apresentando resultado positivo na soroaglutinação e 1 dos 43 soros negativos na soroaglutinação apresentando resultado positivo na fixação de complemento. Entre os animais com abscesso de cernelha, a concordância entre os dois testes foi de $91,7 \%$, com 4 dos 31 soros negativos na fixação de complemento apresentando resultado positivo na soroaglutinação, e todos os 27 soros negativos na soroaglutinação apresentando também resultado negativo na fixação de complemento. A se adotar o título 1/ 100 como ponto de corte, a concordância entre as duas provas aumentou para $93,6 \%$ entre os animais clinicamente sadios, mas diminuiu para $87,5 \%$ entre os animais com abscesso de cernelha.

Entre o teste rosa Bengala e a reação de fixação de complemento observou-se concordância de $93,6 \%$, quando - foram testados animais clinicamente sadios, sendo que 1 dos 45 soros negativos no rosa Bengala apresentou resultado positivo na fixação de complemento, e 2 dos soros negativos nesta prova apresentaram resultado positivo no rosa Bengala. Ao se testarem animais com abscesso de cernelha, a concordância entre os dois testes foi de $97,9 \%$, havendo apenas um soro com resultados divergentes entre as duas provas, isto é, apresentou resultado positivo no rosa Bengala e negativo na fixação de complemento (Tabela 4).
Tabela 1: Títulos de anticorpos contra Brucella sp. observados por meio da prova de soroaglutinação em placa em eqüinos clinicamente sadios e em eqüinos com abscesso de cernelha, abatidos em Araguari - MG, em 1994.

\begin{tabular}{|c|c|c|c|c|}
\hline \multirow[b]{2}{*}{ Título } & \multicolumn{2}{|c|}{$\begin{array}{c}\text { Clinicamente } \\
\text { Sadios }\end{array}$} & \multicolumn{2}{|c|}{$\begin{array}{c}\text { Abscesso de } \\
\text { Cernelha }\end{array}$} \\
\hline & $\mathrm{n}^{\circ}$ & $\%$ & $n^{\circ}$ & $\%$ \\
\hline Nenhum título & 36 & 73,5 & 24 & 50,0 \\
\hline $1 / 25$ & 9 & 18,4 & 3 & 6,3 \\
\hline $1 / 50$ & 2 & 4,1 & 6 & 12,5 \\
\hline $1 / 100$ & 2 & 4,1 & 7 & 14,6 \\
\hline $1 / 200$ & 0 & 0 & 4 & 8,3 \\
\hline $1 / 400$ & 0 & 0 & 4 & 8,3 \\
\hline Total & 49 & 100,0 & 48 & 100,0 \\
\hline
\end{tabular}

Tabela 2: Títulos de anticorpos contra Brucella sp. observados por meio da reação de fixação de complemento em eqüinos clinicamente sadios e em eqüinos com abscesso de cernelha, abatidos em Araguari - MG, em 1994.

\begin{tabular}{ccccc}
\hline & \multicolumn{2}{c}{$\begin{array}{c}\text { Clinicamente } \\
\text { Sadios }\end{array}$} & \multicolumn{2}{c}{$\begin{array}{c}\text { Abscesso de } \\
\text { Cernelha }\end{array}$} \\
\cline { 2 - 5 } Título & $\mathrm{n}^{\circ}$ & $\%$ & $\mathrm{n}^{\circ}$ & $\%$ \\
\hline Nenhum título & 47 & 97,9 & 31 & 62,0 \\
$1 / 2$ & 0 & 0,0 & 1 & 2,0 \\
$1 / 4$ & 0 & 0,0 & 1 & 2,0 \\
$1 / 8$ & 1 & 2,1 & 1 & 2,0 \\
$1 / 16$ & 0 & 0,0 & 2 & 4,0 \\
$1 / 32$ & 0 & 0,0 & 2 & 4,0 \\
$1 / 64$ & 0 & 0,0 & 3 & 6,0 \\
$1 / 128$ & 0 & 0,0 & 4 & 8,0 \\
$1 / 256$ & 0 & 0,0 & 5 & 10,0 \\
\hline Total & 0 & 100,0 & 50 & 100,0 \\
\hline
\end{tabular}

Tabela 3: Resultados da pesquisa de anticorpos contra Brucella sp., por meio do teste rosa Bengala, em eqüinos clinicamente sadios e em eqüinos com abscesso de cernelha, abatidos em Araguari - MG, em 1994.

\begin{tabular}{ccccc}
\hline & \multicolumn{2}{c}{$\begin{array}{c}\text { Clinicamente } \\
\text { Sadios }\end{array}$} & \multicolumn{2}{c}{$\begin{array}{c}\text { Abscesso de } \\
\text { Cernelha }\end{array}$} \\
\cline { 2 - 5 } Resultado & $\mathrm{n}^{0}$ & $\%$ & $\mathrm{n}^{0}$ & $\%$ \\
\hline Negativo & 47 & 95,9 & 30 & 62,5 \\
Positivo & 2 & 4,1 & 18 & 37,5 \\
\hline Total & 49 & 100,0 & 48 & 100,0 \\
\hline
\end{tabular}


Tabela 4: Concordância observada entre os testes realizados para Brucella sp., em eqüinos clinicamente sadios e em eqüino com abscesso de cernelha, abatidos em Araguari - MG, em 1994.

\begin{tabular}{|c|c|c|}
\hline \multirow[b]{2}{*}{ Teste realizado } & \multicolumn{2}{|c|}{ Concordância (\%) } \\
\hline & $\begin{array}{l}\text { Clinicamente } \\
\text { sadios }\end{array}$ & $\begin{array}{c}\text { Abscesso de } \\
\text { cernelha }\end{array}$ \\
\hline TRB $\times \operatorname{SAP}(1 / 50)$ & 95,9 & 93,7 \\
\hline $\operatorname{TRB} \times \operatorname{SAP}(1 / 100)$ & 100,0 & 85,4 \\
\hline $\operatorname{RFC} \times \operatorname{SAP}\left(1 / 50^{*}\right)$ & 89,4 & 91,7 \\
\hline $\operatorname{RFC} \times \operatorname{SAP}\left(1 / 100^{\prime}\right)$ & 93,6 & 87,5 \\
\hline RFC $\times$ TRB & 93,6 & 97,9 \\
\hline
\end{tabular}

TRB = Teste rosa Bengala

SAP = Soroaglutinação em placa

RFC = Reação de fixação de complemento

${ }^{*}=$ Ponto de corte

\section{Discussão}

$O$ fato de a brücelose eqüina poder manifestar-se sob várias formas clínicas (Denny, 1973) e o fato de outros agentes poderem causar o mesmo sintoma dessa enfermidade (Rashmir-Raven et al., 1990) ressaltam a importância do diagnóstico laboratorial e a necessidade do uso de provas sorológicas mais específicas.

No presente trabalho, observou-se que a prova de soroaglutinação em placa, admitindo-se como ponto de corte o título $1 / 50$, foi o teste que revelou maior proporção de resultados positivos, tanto entre os animais sem sintoma $(8,2 \%$, contra $4,1 \%$ do rosa Bengala e $2,1 \%$ da fixação de complemento) como entre animais com sintoma $(43,7 \%$, contra $37,5 \%$ do rosa Bengala e $36,0 \%$ da fixação de complemento), mas ao se adotar o título $1 / 100$, a proporção de positivos caiu para $4,1 \%$ entre os animais clinicamente sadios e para $31,2 \%$ entre os animais com abscesso de cernelha. A reação de fixação de complemento revelou menor proporção de reagentes, o que é condizente com o fato de essa prova apresentar maior especificidade que as outras duas e é compatível com os resultados observados por O'Sullivan (1981), que estudou casos de brucelose eqüina na Austrália.

Os dados do presente trabalho mostraram maior dependência entre a presença ou não do sintoma e os resultados da prova de fixação de complemento, em comparação com os resultados das duas outras provas, e mostraram também que o teste que apresentou maior con- cordância com a fixação de complemento foi o teste rosa Bengala, permitindo concluir quie a fixação de complemento seria o teste mais indicado para uso no diagnóstico confirmatório, de modo a diminuir a ocorrência de resultados falso-positivos proporcionados pela prova de soroaglutinação em placa. Os resultados do presente trabalho mostraram também que, em comparação com a reação de fixação de complemento, a prova de soroaglutinação em placas apresentou maior concordância, ao serem testados animais clinicamente sadios, quando se adotou o título 1/100 como ponto de corte, mas ao serem testados animais com abscesso de cernelha, maior concordância entre as duas provas foi observada quando se adotou o título 1/50 como limiar de positividade (Tabela 4).

A reação de fixação de complemento, por basear-se na detecção de $\operatorname{lgG} 1$, a qual está presente na resposta sorológica em infecções crônicas por Brucella sp., é uma prova mais específica que as provas de aglutinação, as quais, por detectarem IgM, podem estar mais sujeitas à ocorrências de reações falso-positivas.

Assim como observado no presente trabalho, animais com o sintoma e sem títulos sorológicos e animais sem o sintoma e com títulos sorológicos foram observados também por Dawson (1977) e por O'Sullivan (1981), o que está associado ao fato de ser comum a infecção assintomática e também ao fato de o sintoma poder ser provocado por outro agente. Os autores alertam ainda que o animal pode ter tido contato com o agente etiológico e desenvolvido resposta humoral sem a ocorrência de infecção persistente. De acordo com Cohen et al. (1992), a presença de anticorpos indica exposição ao agente etiológico e não necessariamente infecção corrente.

Para um diagnóstico mais seguro da brucelose eqüina, além da observação da sintomatologia clínica, seria importante a realização de sorologia com amostras pareadas, conforme indica Denny (1973); o isolamento do agente etiológico; e o histórico de convivência com rebanhos (principalmente bovinos), em áreas onde a enfermidade é endêmica.

$O$ isolamento ou não do agente etiológico (o que não pôde ser feito no presente trabalho) deve ser interpretado com cautela. O isolamento e identificação de Brucella sp. em material da lesão permite a confirmação do diagnóstico, porém podem ser isolados outros microrganismos desse material, já que a Brucella sp. pode ter seu crescimento suplantado pelo crescimento mais rápido de bactérias contaminantes (Cohen et al., 1992).

\begin{abstract}
The purpose of this work was to verify the relationship between antibodies to Brucella sp. and clinical signs compatible with equine brucellosis. Fifty sera obtained from animals with fistulous withers and 50 sera from animals without this sign were examined by the plate agglutination, complement fixation and rose Bengal. Analyzing, by the $\mathrm{X}^{2}$, the relationship between the presence or absence of fistulous withers and the results of serological tests, a dependence between the distribution of the frequences was observed $(P>0.005)$, with $X^{2}$ showing values of 12.30 for the agglutination test
\end{abstract}


adopting the titre $1 / 100$ as the cut-off; 16.06 for this test adopting the titre $1 / 50$ as the cut-off; 16.53 for the rose Bengal test; and 18.04 for the complement fixation test. The results of this work showed that, although the presence of bursitis in horse can not be always associated with brucellosis, there is a strong relationship between this sign and antibodies to Brucella sp., and that complement fixation was the test showing greater proportion of negative results among animals without the clinical sign.

Keywords: Equine brucellosis; serological diagnosis

\section{Referências bibliográficas}

ALTON, G.G. et al. Techniques for the brucellosis laboratory. Paris : INRA, 1988. $190 \mathrm{p}$.

CENTRO PANAMERICANO DE ZOONOSIS, Ramos Mejia. Técnicas e interpretación de las pruebas de seroaglutinación para el diagnóstico de la brucelosis bovina. Ramos Mejia, 1968. 9 p. (Nota tecnica, n. 2, rev. 1).

COHEN, N.D., CARTER, G.K., McMULAN, W.C. Fistulous withers in horses : 24 cases (1984-1990). J. Am. Vet. Med. Assoc., v. 201, no. 1, p. 121-124, 1992.

DAWSON, F.L.M. Further serological reactions to Brucella antigen in the horse. Eq. Vet. J., v. 9, no. 3, p. 158-160, 1977.

DENNY, H.R. A review of brucellosis in the horse. Eq. Vet. J., v. 5, no. 3, p. 121-125, 1973.

GAUGHAN, E.M., FUBINE, S.L., DIETZE, A. Fistulous withers in horses: 14 cases (1978-1987). J. Am. Vet. Med. Assoc., v. 193, p. 964-966, 1988.

GODOY, A.M., BARG, L. Aspectos ecológicos da infecção brucélica. 2- Investigação sorológica em cavalos de corrida. Arq. Esc. Vet. UFMG, v. 28, n. 2, p. 121-123, 1976.
JARDIM, E.C. et al. Presença de aglutininas anti-Brucella em eqüinos no Estado de Goiás. Anais da E.A.V. - UFGo, v. 8, n. 1, p. 151-155, 1978.

LANGENEGGER, J., SZECHY, A.M. Brucelose em eqüídeos domésticos - isolamento da Brucella abortus de bursites da cernelha no Brasil. Arq. Inst. Biol. An., v. 4, p. 49-63, 1961.

MARTIN, S. W., MEEK, A.H., WILLEBERG, P. Veterinary epidemiology. Principles and methods. Ames: lowa State University Press, 1987.

OLIVEIRA, Q.C., MOREIRA, V.S., LIMA, C.S. Brucelose em eqüinos. R. Med. Vet., v. 9, n. 2, p. 93-106, 1973.

O'SULLIVAN, B.M. Brucella abortus titres and bursitis in the horse. Aust. Vet. J., v. 57, p. 103-104, 1981.

RASHMIR-RAVEN, A., GAUGHAN, E.M., MODRANSDKY, P. et al. Fistulous withers. Compend. Contin. Educ. Pract. Vet., v. 12, p. 1633-1641, 1990.

VIANA, F.C., REIS, R., SANTOS, W.L.M. Inquérito sorológico para brucelose eqüina em Minas Gerais. Arq. Esc. Vet. UFMG, v. 33, n. 3, p. $431-435,1981$. 